\title{
Shape correlates of visual and tactual size judgments: A contrast with complexity'
}

DEAN H. OWEN ${ }^{2}$

OHIO STATE UNIVERSITY

Pattern correlates of perceived size were studied by obtaining category judgments of the size of 100 random forms from $40 \mathrm{Ss}$ who explored the forms visually and $40 \mathrm{Ss}$ who explored them tactually. Comparison of the modalities and contrasts with perceived complexity were made via intercorrelations of judgments and latencies, multiple regression analyses using factored form dimensions, and correlations with original form measures. By holding area of the forms constant, it was shown that perceived size can be related to characteristics of shape.

Two visual studies pertaining to apparent size of complicated forms have shown discrepant results. Arnoult (1960) had Ss rate the size of a sample of Attneave and Arnoult (1956) Method I randomly derived shapes and found that the area of the forms accounted for most of the variance in the judgments, while other physical variables added very little to a multiple correlation. He concluded that apparent size, contrary to expectation, was almost a unidimensional psychophysical continuum. Hitchcock, Brown, Michels, and Spiritoso (1962) questioned the statement made by Arnoult on the basis of results obtained from an experiment in which Ss judged whether figures from the Vanderplas and Garvin (1959) Method I sample were "larger" or "smaller" than a standard figure of median area within a given sidedness level. Working within five levels of sidedness, they found that errors in judgment were a positive function of the number of sides in a figure, suggesting that judgment of size is a multivariate response to a stimulus complex rather than a simple correlate of area.

Of prime importance is the fact that other physical variables, e.g., total sides, perimeter, and symmetry, correlated highly with size judgments in the Arnoult study. That these variables did not account for much variance in addition to area is very likely attributable to the fact that as a function of this method of generating forms, these same measures vary positively with area. Since area may be varied at will and is not a property of shape per se, holding area constant should allow the effects of true shape parameters to be assessed.

Shape correlates of perceptual judgments can be determined by correlating a large number of form measures with Ss' ratings and by using factored dimensions obtained from the same form measures to account for variability in ratings via multiple regression (Brown \& Owen, 1967). The same procedures were used to demonstrate perceptual equivalence of the visual and tactual modalities in a complexity judgment task, where over $90 \%$ of the rating variability was accounted for by as few as four predictors (Owen \& Brown, 1970a). It was assumed that if area were held constant, variation in size judgments could be accounted for by measurable properties of shape.

\section{Subjects \\ METHOD \\ Eighty male undergraduates enrolled in the introductory psychology course at Ohio State University served as $S s$ in fulfillment of a course requirement. Forty participated in the visual experiment and 40 served in the tactual experiment.}

\section{Stimuli and Experimental Design}

Design and execution of the experiments followed the complexity judgment study (Owen \& Brown, 1970a) as closely as possible so that results could be compared. The same 100 forms sampled from the 1,000 Attneave and Arnoult (1956) Method I angular, closed polygons generated by Brown and Owen (1967) were used in the size judgment experiments. Twenty forms at each of the following levels: $4,8,12,16$, and 20 sides, were equated to 1,250 square units area and plotted in a $100 \times 100 \mathrm{~mm}$ coordinate system. The tactual stimuli were constructed from Behr-Manning 360A abrasive paper, analogous to very fine sandpaper, and glued onto $100 \times 100 \mathrm{~mm}$ squares of smooth poster board. The visual stimuli were presented black on a white background, with the same area as the tactual forms, on a rear-projection screen. Order of presentation of forms was randomized by a computer program for each $S$, with the restriction that one form from each side class be represented in each consecutive block of five forms.

\section{Apparatus and Procedure}

Each $\mathrm{S}$ was given a 7-point adjective scale that ranged from "extremely small" through "medium" to "extremely large."
When $S$ had memorized the scale, he explored 10 practice forms to acquaint himself with the range of size. The forms were presented by means of apparatus that also provided for measurement of the time from the point at which $S$ exposed the stimulus to himself to the point at which he made a judgment of the size of the stimulus by assigning it to one of the scale categories. His verbal response stopped a 1/100-sec timer by operation of a voice key. Ratings and latencies were recorded.

\section{RESULTS}

Ratings

For the purpose of numerical analysis, the adjectival ratings were converted to a scale from 1 to 7 , corresponding to the category labels from "extremely small" to "extremely large." Means computed across the $40 \mathrm{Ss}$ provided a size value for each form and means of the 20 forms were taken to represent each sidedness level. The sidedness means are presented in Fig. 1, showing three standard deviations of the 20 form means above the sidedness mean for the visual ratings and below the sidedness mean for the tactual ratings. An analysis of variance revealed that the ratings did not differ significantly between modalities or across sidedness levels within

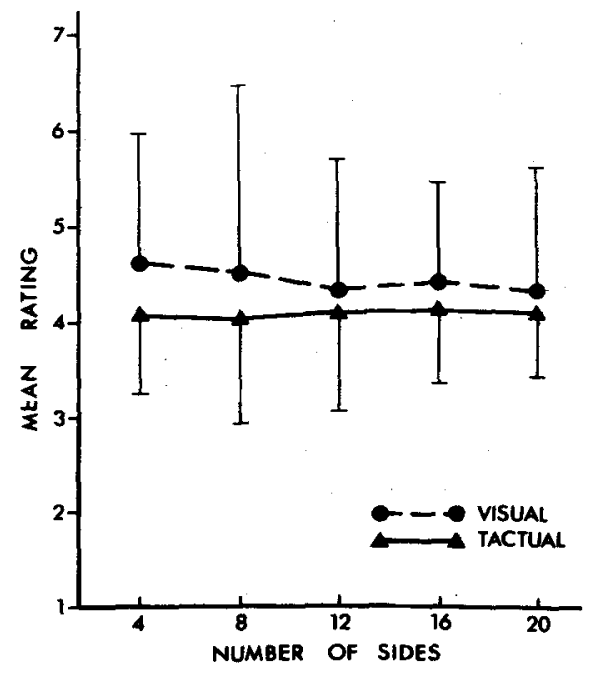

Fig. 1. Mean size rating at each sidedness level with three standard deviations of the 20 form means shown above the visual means and below the tactual means. 
either modality, and that the Modality by Sides interaction was not significant. Forms varied significantly $(p<.01)$ within both modalities, providing variation in judged size necessary for correlation with physical dimensions. A significant $(p<.01)$ Modalities by Forms within Sides interaction indicated a difference in size judgments within sidedness levels, depending on the input modality.

The 10 factors that were correlated with the dependent variables were obtained by principal components factorization of the 80 Brown and Owen (1967) measures using used in a previous complexity study (Owen \& Brown, 1970a), comparison of the two tasks was possible. Table 1 contains correlations of the dependent variables with the three factors that accounted for more than a small per cent of variance. The tactual complexity ratings were not included since they correlated .98 with visual complexity ratings. Correlations with original measures were computed to show what kinds of cues were related to performance as well as to aid in all 100 forms. Since the same forms were

interpretation of what stimulus information was represented by the factors. Measures were selected for their high factor loading. Table 2 contains correlations among the physical dimensions clustered according to the kinds of information they represent. Correlations of the original measures with the factors are factor loadings.

From the correlations among dependent variables, it was apparent that size and complexity judgments are relatively independent. Correlations with the various physical dimensions confirmed the fact that different information was being used in the two cases. Although the correlation between visual and tactual size ratings is not as high as between complexity ratings for the two modalities, the two sets of size ratings tended to correlate with measures of dispersion and elongation. As shown by the correlation with number of sides, tactual size ratings were more influenced by the complexity of the forms than were visual size ratings. Visual size latencies had little relation to either physical variables or other dependent variables.

Table 1

Correlations of Dependent Variables with Relevant Factors (F) and Selected Measures (M), Multiple Correlation (R) with the Factors, and Correlations Among the Deperdent Variables

\begin{tabular}{|c|c|c|c|c|c|}
\hline & $\begin{array}{c}\text { Visual } \\
\text { Size } \\
\text { Ratings }\end{array}$ & $\begin{array}{c}\text { Tactual } \\
\text { Size } \\
\text { Ratings }\end{array}$ & $\begin{array}{c}\text { Tactual } \\
\text { Size } \\
\text { Latencies } \\
\end{array}$ & $\begin{array}{c}\text { Tactual } \\
\text { Complexity } \\
\text { Latencies }\end{array}$ & $\begin{array}{c}\begin{array}{c}\text { Visual } \\
\text { Complexity } \\
\text { Ratings }\end{array} \\
\end{array}$ \\
\hline $\begin{array}{l}F_{1} \\
M_{22} \\
M_{35} \\
M_{77}\end{array}$ & $\begin{array}{l}.60 \\
.75 \\
.69 \\
.67\end{array}$ & $\begin{array}{l}.48 \\
.61 \\
.56 \\
.60\end{array}$ & $\begin{array}{l}.10 \\
.23 \\
.15 \\
.28\end{array}$ & $\begin{array}{r}-.03 \\
.09 \\
-.03 \\
.16\end{array}$ & $\begin{array}{r}-.13 \\
.02 \\
-.11 \\
.07\end{array}$ \\
\hline $\begin{array}{l}\mathbf{F}_{2} \\
\mathbf{M}_{10} \\
\mathbf{M}_{23} \\
\mathbf{M}_{81}\end{array}$ & $\begin{array}{r}.07 \\
-.06 \\
.15 \\
-.21\end{array}$ & $\begin{array}{l}.33 \\
.16 \\
.37 \\
.08\end{array}$ & $\begin{array}{l}.77 \\
.74 \\
.77 \\
.73\end{array}$ & $\begin{array}{l}.88 \\
.91 \\
.86 \\
.89\end{array}$ & $\begin{array}{l}.92 \\
.95 \\
.89 \\
.93\end{array}$ \\
\hline $\begin{array}{l}F_{6} \\
M_{51}\end{array}$ & $\begin{array}{r}-.37 \\
.44\end{array}$ & $\begin{array}{r}-.18 \\
.31\end{array}$ & $\begin{array}{r}-.07 \\
.11\end{array}$ & $\begin{array}{r}.05 \\
-.01\end{array}$ & $\begin{array}{r}.05 \\
-.01\end{array}$ \\
\hline $\mathbf{R}$ & .71 & .61 & .78 & .88 & .93 \\
\hline $\begin{array}{l}\text { VSR } \\
\text { TSR } \\
\text { TSL } \\
\text { TCL } \\
\text { VCR }\end{array}$ & - & $\begin{array}{l}.63 \\
-\end{array}$ & $\begin{array}{l}.14 \\
.34 \\
-\end{array}$ & $\begin{array}{r}-.02 \\
.21 \\
.77 \\
-\end{array}$ & $\begin{array}{r}-.10 \\
.19 \\
.77 \\
.95 \\
-\end{array}$ \\
\hline
\end{tabular}

$r(100 d f)=.3211, p<.001$

M22 Vertical extent $x$ horizontal extent

M35 Largest complementary radial pair

M77 Maximum second perimeter moment

M10 Mean of interior angles

$M 23$ Length of perimeter

M81 Number of sides

M51 Variance of area in four vertical columns

Table 2

Correlations of Factors and Measures

\begin{tabular}{|c|c|c|c|c|c|c|c|c|c|c|}
\hline & $F_{1}$ & $\mathbf{M}_{22}$ & $M_{35}$ & $\mathrm{M} 77_{77}$ & $\mathrm{~F}_{2}$ & $\mathrm{M}_{10}$ & $\mathrm{M}_{23}$ & $M_{81}$ & $F_{6}$ & M51 \\
\hline $\begin{array}{l}F_{1} \\
M_{22} \\
M_{35} \\
M_{77}\end{array}$ & - & $\begin{array}{c}.83 \\
-\end{array}$ & $\begin{array}{l}.87 \\
.80 \\
-\end{array}$ & $\begin{array}{l}.92 \\
.83 \\
.88 \\
-\end{array}$ & $\begin{array}{l}.00 \\
.17 \\
.08 \\
.24\end{array}$ & $\begin{array}{r}-.09 \\
.06 \\
-.11 \\
.08\end{array}$ & $\begin{array}{l}.10 \\
.26 \\
.17 \\
.34\end{array}$ & $\begin{array}{r}-.15 \\
-.09 \\
-.15 \\
.03\end{array}$ & $\begin{array}{r}.00 \\
-.31 \\
-.17 \\
-.08\end{array}$ & $\begin{array}{l}.12 \\
.38 \\
.25 \\
.17\end{array}$ \\
\hline $\begin{array}{l}\mathbf{F}_{2} \\
\mathbf{M}_{10} \\
\mathbf{M}_{23} \\
\mathbf{M}_{81}\end{array}$ & & & & & - & $\begin{array}{l}.90 \\
-\end{array}$ & $\begin{array}{l}.98 \\
.85 \\
-\end{array}$ & $\begin{array}{l}.87 \\
.88 \\
.85 \\
-\end{array}$ & $\begin{array}{r}.00 \\
.05 \\
-.03 \\
.09\end{array}$ & $\begin{array}{r}.06 \\
.01 \\
.07 \\
-.12\end{array}$ \\
\hline $\begin{array}{l}F_{6} \\
M_{51}\end{array}$ & & & & & & & & & - & -.76 \\
\hline
\end{tabular}

\section{Latencies}

Figure 2 shows latency to make judgments of size and complexity while gaining information tactually. Both variables were logarithmically related to number of sides, but, with the exception of four-sided figures, exploring a form for the purpose of making a complexity judgment takes increasingly more time than gaining information for a size rating. While tactual size latencies tended to be most highly related to physical and judged complexity, they had higher correlations with size ratings and the physical correlates of size ratings than did the complexity variables.

\section{DISCUSSION}

Accounting for a significant proportion of variation in size judgments with physical stimulus variation demonstrated that perceived size is not a univariate function of area. Deviations from compactness, in the form of general dispersion of the figure or of elongation, result in a pattern being judged larger. As shown by Arnoult (1960), area is a dominant cue for perceived size, but shape correlates, being more subtle, may be investigated by holding the dominant cue constant. Under the theoretical notion that performance in a perceptual task is a function of weighting various stimulus characteristics, it is reasonable to expect the incoming information to have a strong influence in determining the weights. If there is a very salient cue, use of other cues tends to be suppressed to the point of minimal or no influence. When the dominant cue is eliminated, $S$ must search for more subtle variation in order to perform the task.

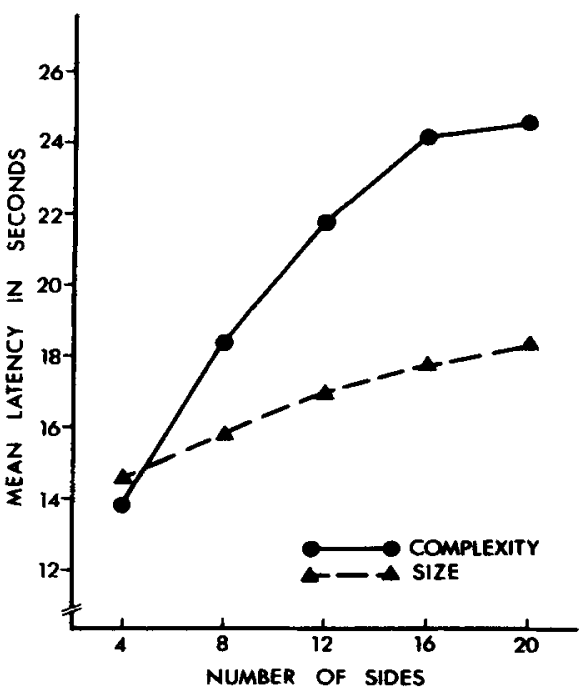

Fig. 2. Mean tactual latency at each sidedness level for the complexity and size judgment tasks. 
Evidence of task difficulty, in addition to complaints by Ss of little difference in size, came from frequency counts of how many times each judgment category was used. While the relatively easy complexity task generated approximately equal use of all seven categories, the size task revealed a distribution showing frequent use of the middle categories with very little use of the extreme categories. That less variance was accounted for in the judgments of size (50\%) than complexity (90\%) was probably partly a function of lower stability in the size ratings due to the difficult nature of the task.

Although no relationship was found between size ratings and number of sides, Hitchcock et al (1962) observed an increase in errors of comparative judgment as number of sides increased. The different results can perhaps be explained by the fact that they used the Vanderplas and Garvin (1959) forms, which were not equated for area. Even though mean area of Method I forms increases with number of sides, variation in area may be restricted by the fixed area of the grid in which the forms are generated. If forms become more similar in other correlates of size as number of sides increases, then for ratings, variation about the sidedness mean should decrease, but no such trend was found. The only trend observed, in fact, was for greater variability in size ratings of eight-sided forms, where several studies have shown optimal discrimination (Brown, Hitchcock, \& Michels, 1963; Owen \& Brown, 1970b).
Visual and tactual size judgments tended to have commonality in correlation with the form characteristics represented by Factor I, but differ in other correlates. The difference in latencies to make tactual judgments of size and complexity indicates that Ss were not picking up as precise information in the size task, but did take more time to explore the more complex forms, even though complexity had no influence on the size judgments. Independence of the size and complexity ratings allowed a graphic demonstration of the utility of multivariate psychophysics. By measuring a large number of potential cues for correlation with performance, an estimate of stimulus cue utilization can be made. An inherent problem in the use of factor dimensions was illustrated by the higher correlation of size ratings with original measures than with the factor upon which those measures loaded. Only when the perceptually relevant measured characteristic has an extremely high loading on a factor can that factor be said to actually represent the information used. Correlation of a dependent variable with more potential cues than $S$ could possibly use is the most certain means of identifying effective cues for further study. Through use of this technique, it was concluded that judgments of size depend on more than just area, since, when area was held constant, variability in size judgments was found to be related to physical characteristics of shape.

\section{REPERENCES}

ARNOULT, M. D. Prediction of perceptual responses from structural characteristics of the stimulus. Perceptual \& Motor Skills, 1960, 11. 261-268.

ATTNEAVE, F., \& ARNOULT, M. D. The quantitative study of shape and pattern perception. Psychological Bulletin, 1956, 53. 452-471.

BROWN, D. R., HITCHCOCK, L., JR., \& MICHELS, K. M. Quantitative studies in form perception: An evaluation of the role of selected stimulus parameters in the visual discrimination performance of human subjects. Perceptual \& Motor Skills, 1962, 14, 519-529.

BROWN, D. R., \& OWEN, D. H. The metrics of visual form: Methodological dyspepsia. Psychological Bulletin, 1967, 68, 243-259.

HITCHCOCK, L., JR., BROWN, D. R., MICHELS, K. M., \& SPIRITOSO, T. Stimulus complexity and the judgment of relative size. Perceptual \& Motor Skills, 1962, 14, 210.

OWEN, D. H., \& BROWN, D. R. Visual and tactual form complexity: A psychophysical approach to perceptual equivalence. Perception \& Psychophysics. 1970a, 7. 225-228.

OWEN, D. H., \& BROWN, D. R. Visual and tactual form discrimination: Psychophysical comparison within and between modalities. Perception \& Psychophysics, 1970b, 7, 302 306.

VanuextLAS, J. M., \& GARVIN, E. A. The association value of random shapes. Journal of Experimental Psychology, 1959, 57, 147-154.

\section{NOTES}

1. This research was supported by Research Grant MH-12592 from the National Institute of Mental Health.

2. Address: Department of Psychology, The Ohio State University, Columbus, Ohio 43210.

(Accepted for publication October 1S, 1969.) 